\title{
Treatment of Stage I Nsclc in High Risk Patients: Surgery Versus Radiotherapy
}

\author{
Antonacci F $^{1}$, Schiavon $\mathbf{M}^{2}$, Guiducci ${ }^{1}$, Kawamukai $\mathrm{K}^{1}$, Forti Parri SN ${ }^{1}$, Boaron M1 and Di Saverio S ${ }^{3 *}$
}

${ }^{1}$ Division of Thoracic Surgery, Maggiore and Bellaria Hospitals, Bologna, Italy

${ }^{2}$ Division of Thoracic Surgery, University Hospital of Padova, Padova, Italy

${ }^{3}$ Division of Emergency Surgery, Maggiore Hospital, Bologna, Italy

Surgery represents the cornerstone of therapy for NSCLC, however in high risk patients, surgical approach may be discouraged due to high rates of postoperative morbidity and mortality. In not surgically treatable patients, radiation therapy, in particular, stereotactic ablative radiotherapy (SABR) has replaced conventional radiotherapy due to higher local control rate, lower toxicity and lower adverse effect on quality of life and pulmonary function [1].

Several methods have been proposed to identify perioperative risk of patients undergoing surgery for lung cancer: the Thoracoscore assessed the risk of in hospital mortality, another system identified predictors of prolonged hospitalization after lung lobectomy and a scoring system predicting the risk of ICU admission after major lung resection was proposed [2-4].

To evaluate the risk in lung surgery we need to consider factors related to the patient (age, respiratory function and other comorbidities) and factors related to the surgical procedure (amount of the resection and surgical approach).

Advanced age is no longer considered a contraindication to surgery, a careful evaluation and selection is necessary to identify patients who will benefit most from resection [5]. General status of the patient, considering all the comorbidities should be considered. Respiratory function is the main factor in the preoperative evaluation and exact criteria have been estabilished to consider a patient fit for surgery [6].

In patients with marginal pulmonary function or significant comorbidities, sublobar resections are a valid alternative, moreover video assisted thoracoscopic procedure gives the potential benefits of equivalent oncologic outcomes and less morbidity [7].

Lung lobectomy is the treatment of choice in early stage NSCLC [7]. In high risk patients this procedure cannot be performed and a wedge resection or an anatomic sublobar segmentectomy is usually carried out, moreover this procedure has been proposed as curative in minimally invasive adenocarcinoma, formerly bronchioalveolar carcinoma [8].

In our institution 151 patients underwent wedge resection for cT12 NSCLC. The 5 year survival for cT1 was $60.3 \%$, for cT2 was $40.8 \%$. We observed a mortality of $0.6 \%$ ( 1 patient deceased for a bleeding duodenal ulcer) and a morbidity of $17.3 \%$ (27 patients: 9 pulmonary complication, 5 cardiac complications, 6 hemhorrages, 3 prolonged air leak, 2 empyema, 2 chylotoraces). The high rate of comorbidities can be explained by the fact that all these patients were considered at high risk, not fit for lobectomy and consequently more inclined to develop complications. Our results were comparable to those reported in literature.

SABR has recently gained an important role in the treatment of NSCLC, in particular it should be regarded as the standard of care for patients with inoperable Stage I and should be at least considered for marginally operable patients [9].
The excellent local control and low toxicity of SABR have challenged the assumption that surgery is the preferred treatment for patient with potentially operable stage I NSCLC [1].

This technique has reported a 3 year survival of $37-53 \%$ for patients receiving a biologic equivalent dose of less than $100 \mathrm{~Gy}$ and of $48-91 \%$ for patients receiving a biologic equivalent dose of $100 \mathrm{~Gy}$ or more. The reported rate of complication was $0-10 \%$ for the patients in the first group and $0-11 \%$ for the patients in the second group, morbidities included pneumonitis, rib fractures, pleural effusion and skin reaction [10].

Surgery remains the standard for early stage lung cancer. Recent studies showed that SABR reported results comparable to operative treatment. Randomized comparative trials of surgery and SABR are underway to define their role in the treatment of lung neoplasm.

\section{References}

1. Lagerwaard FJ, Verstegen NE, Haasbeek CJ, Slotman BJ, Paul MA, et al. (2012) Outcomes of stereotactic ablative radiotherapy in patients with potentially operable stage I non-small cell lung cancer. Int J Radiat Oncol Bio Phys 83: 348-353

2. Falcoz PE, Conti M, Brouchet L, Chocron S, Puyraveau M, et al. (2007) The Thoracic Surgery Scoring System (Thoracoscore): risk model for in-hospital death in 15,183 patients requiring thoracic surgery. J Thorac Cardiovasc Surg 133: $325-332$.

3. Wright CD, Gaissert HA, Grab JD, O'Brien SM, Peterson ED, et al. (2008) Predictors of prolonged length of stay after lobectomy for lung cancer: a Society of Thoracic Surgeons General Thoracic Surgery Database risk-adjustment model. Ann Thorac Surg 85: 1857-1865

4. Pieretti P, Alifano M, Roche N, Vincenzi M, Forti Parri SN, et al. (2006) Predictors of an appropriate admission to an ICU after a major pulmonary resection. Respiration 73: 157-165.

5. Dominguez-Ventura A, Cassivi SD, Allen MS, Wigle DA, Nichols FC, et al. (2007) Lung cancer in octogenarians: factors affecting long-term survival following resection. Eur J Cardiothorac Surg 32: 370-374.

6. Colice GL, Shafazand S, Griffin JP, Keenan R, Bolliger CT (2007) American College of Chest Physicians. Physiologic evaluation of the patient with lung cancer being considered for resectional surgery: ACCP evidenced-based clinical practice guidelines (2nd edition). Chest 132: 161S-77S.

7. Pennathur A, Abbas G, Christie N, Landreneau R, Luketich JD (2007) Video assisted thoracoscopic surgery and lobectomy, sublobar resection, radiofrequency ablation, and stereotactic radiosurgery: advances and

*Corresponding author: Di Saverio S, Division of Emergency Surgery, Maggiore Hospital, Bologna, Italy, E-mail: salo75@inwind.it

Received April 04, 2013; Accepted May 18, 2013; Published May 20, 2013

Citation: Antonacci F, Schiavon M, Guiducci G, Kawamukai K, Forti Parri SN, et al. (2013) Treatment of Stage I Nsclc in High Risk Patients: Surgery Versus Radiotherapy. J Nucl Med Radiat Ther S2: e002. doi:10.4172/2155-9619.S2-e002

Copyright: (c) 2013 Antonacci F, et al. This is an open-access article distributed under the terms of the Creative Commons Attribution License, which permits unrestricted use, distribution, and reproduction in any medium, provided the original author and source are credited. 
Citation: Antonacci F, Schiavon M, Guiducci G, Kawamukai K, Forti Parri SN, et al. (2013) Treatment of Stage I Nsclc in High Risk Patients: Surgery Versus Radiotherapy. J Nucl Med Radiat Ther S2: e002. doi:10.4172/2155-9619.S2-e002

Page 2 of 2

controversies in the management of early stage non-small cell lung cancer. Curr Op Pulm Med 13: 267-270.

8. Koike T, Togashi K, Shirato T, Sato S, Hirahara H, et al. (2009) Limited resection for noninvasive bronchioloalveolar carcinoma diagnosed by intraoperative pathologic examination. Ann Thorac Surg 88: 1106-1111.
9. Andratschke N (2012) Stereotactic ablative radiotherapy for inoperable stage NSCLC. Lancet Oncol 13: 746-748

10. Nguyen NP, Garland L, Welsh J, Hamilton R, Cohen D, et al. (2008) Can stereotactic fractionated radiation therapy become the standard of care for early stage non-small cell lung carcinoma. Cancer Treat Rev 34: 719-727.
This article was originally published in a special issue, Surgical oncology: Clinical Importance handled by Editor(s). Dr. Liqiang Zhang, Arizona State University, USA; Dr. Salomone Di Saverio, Surgery and Trauma Surgery Unit, Italy 